\title{
Stability Analyses by HPLC-MS of Guanitoxin Isolated from Sphaerospermopsis torques-reginae
}

\author{
Kelly A. Fernandes, ${ }^{\circledR a}$ Felipe Augusto Dörr ${ }^{a}$ and Ernani Pinto ${ }^{\odot *, a, b}$ \\ ${ }^{a}$ Laboratório de Toxinas e Produtos Naturais de Algas (LTPNA), \\ Departamento de Análises Clínicas e Toxicológicas, Faculdade de Ciências Farmacêuticas, \\ Universidade de São Paulo, Avenida Professor Lineu Prestes, 580, 05508-000 São Paulo-SP, Brazil \\ ${ }^{b}$ Centro de Energia Nuclear na Agricultura (CENA), Universidade de São Paulo, \\ Avenida Centenário, 303, 13416-000 Piracicaba-SP, Brazil
}

\begin{abstract}
Guanitoxin (GNT) is a natural organophosphate produced by some species of freshwater cyanobacteria, which inhibits the active site of acetylcholinesterase, preventing the hydrolysis of cholinesterases and consequently causing serious disturbances in the neuromuscular system. Despite having a chemical structure like synthetic organophosphates, there is still no analytical standard available for environmental and freshwater monitoring. Therefore, this study investigated the stability of GNT under different storage conditions, $\mathrm{pH}$, and temperature. The toxin is produced by the cyanobacterium Sphaerospermopsis torques-reginae and monitored by liquid chromatography coupled to mass spectrometry (LC-MS) and LC-MS/MS for the identification and verification of its stability. The main degradation product formed is the hydroxy-amino-guanidinic derivative of the toxin. The results also indicate that GNT is stable in acidic medium $(\mathrm{pH}=3.0)$, but can gradually degrade at room temperature $\left(>23^{\circ} \mathrm{C}\right.$ ) over a period of $96 \mathrm{~h}$. Lyophilized biomass of $S$. torques-reginae containing GNT remained stable when stored in a refrigerator below $4{ }^{\circ} \mathrm{C}$. In addition, the extraction yield is higher when prepared from fresh $S$. torques-reginae cells than from lyophilized material. Thus, the results shown here contribute with valuable information for studies that aim at the isolation, identification, and monitoring of GNT in samples of raw water and cyanobacterial blooms.
\end{abstract}

Keywords: guanitoxin, anatoxin-a(s), natural organophosphate, acetylcholinesterase, cyanotoxins

\section{Introduction}

Anatoxin-a(s) is a unique organophosphate natural toxin that inhibits cholinesterases. ${ }^{1}$ Recently, because it was easily confused with other cyanobacterial toxins, such as anatoxin and homoanatoxin, which have different structures and distinct mechanism of action, Fiore et al., ${ }^{2}$ proposed changing the name to guanitoxin (GNT), linking the name to the structural characteristic of the guanidine group present in the molecule.

GNT is produced by cyanobacteria and was first described for the species Anabaena flos-aquae (NRC 525-17); its action of mechanism was studied from in vivo tests, showing that GNT was a potent inhibitor of the acetylcholinesterase (AChE) enzyme, preventing the hydrolysis of acetylcholine. ${ }^{3} \mathrm{AChE}$

*e-mail: ernani@usp.br inhibition allows acetylcholine to remain available in muscle stimulation, leading to muscle over excitation. ${ }^{4,5}$ Therefore, the transmission of nerve impulses to muscle cells becomes continuous, causing severe disturbance in the neuromuscular system, such as excessive salivation, muscle tremor and involuntary contractions, convulsions and respiratory failure, and in some cases followed by death. ${ }^{3,5-7}$

Subsequently, its structure was elucidated by Matsunaga et al., ${ }^{1}$ and defined as $(S)$-2-amino5-((dimethylamino)methyl)-4,5-dihydro- $1 H$-imidazol1-yl methyl hydrogen phosphate. After the first GNT report, other cases were reported relating the accidental consumption of contaminated water containing GNT during cyanobacterial blooms. ${ }^{7-9}$ GNT has been reported in some countries in North and South America, Europe, and Asia from samples of cyanobacterial blooms in freshwater and terrestrial environments. ${ }^{3,7,10,11}$ 
GNT cannot be analyzed by gas chromatography and possesses no important chromophore group for UV-Vis detection; therefore, alternative methods have been proposed, mainly using cholinesterase inhibition assays. ${ }^{11,12}$ More recently, liquid chromatography coupled to mass spectrometry (LC-MS) methods that explore the most common GNT loss fragments in positive mode with electrospray ionization, using quadrupole iontrap, triple quadrupole (QqQ), and quadrupole time-of-flight (Q-TOF) mass analyzers, have also been proposed for toxin monitoring and confirmation. ${ }^{13,14}$

Data on this toxin is still very poorly documented compared to other known cyanotoxins. ${ }^{2,15}$ Total chemical synthesis of GNT is not yet available in the literature, only its amino-guanidinic derivative has been partially synthesized. ${ }^{1,16}$ The lack of a commercial analytical standard makes its unambiguous determination very difficult in environmental and biological samples. In addition, GNT can hydrolyze in alkaline medium and high temperature. Probably, its instability in these environmental conditions makes it even more difficult to be detected and identified. ${ }^{1,13}$

Therefore, cases might be neglected because of GNT instability and misdetection. In this work, we conducted a more extensive study on the stability of this cyanotoxin. The stability of GNT was investigated by LC-MS/MS in aqueous samples with different $\mathrm{pH}$ values (acid-neutral base) linked to the variables of temperature and time of exposure. We also evaluated the stability of intracellular GNT in samples of dried cells conditioned at different temperatures for a period of 180 days. Thus, the main objective of this study was to provide results that can be readily utilized as a suitable workflow for sample preparation and preservation of environmental and laboratory material containing GNT.

\section{Experimental}

Reagents

Reagents used to prepare the ASM-1 medium ${ }^{17}$ were of analytical grade (Vetec, Rio de Janeiro, Brazil). Acetonitrile and methanol were of LC-MS grade (Sigma-Aldrich, Darmstadt, Germany). Ammonium formate, sodium hydroxide, formic acid, hydrochloric acid and buffer solutions with $\mathrm{pH} 7.00,4.00$ and 9.00 were obtained from Sigma-Aldrich (Sigma-Aldrich, Darmstadt, Germany). Ultra-pure water was obtained from a Direct-Q8 water purification system (Millipore, Billerica, USA), acetic acid from JBaker (JBaker Phillipsburg, New Jersey, USA), and monobasic potassium phosphate, phosphoric acid and monobasic sodium phosphate from Labsynth (Labsynth, Diadema, Brazil).

\section{Cultivation of ITEP-24 strain}

The experiments were carried out with the strain ITEP-24 obtained from the Technological Institute of Pernambuco (ITEP) isolated in the Tapacurá, Pernambuco, Brazil reservoir. ${ }^{11}$ This species was subsequently classified as Sphaerospermopsis torques-reginae (Komárek) ${ }^{18}$ and confirmed to be a GNT producer. ${ }^{13,14}$ Currently, this strain is part of the cyanobacteria collection in the Laboratory of Toxins and Natural Products of Algae and Cyanobacteria (LTPNA) at the School of Pharmaceutical Sciences, University of São Paulo, Brazil (FCF/USP).

To perform the experiments with fresh culture and dry cells, the strain ITEP-024 was grown in ASM-1 medium ${ }^{17}$ $\mathrm{pH}$ 7.5-8.0, in an incubator under continuous aeration, at a temperature of $22.0 \pm 1.0^{\circ} \mathrm{C}$, and $12 \mathrm{~h}$ photoperiod (Nova Tecnica, São Paulo, Brazil), under light intensity of $40 \mu \mathrm{mol}$ of photons $\mathrm{m}^{-2} \mathrm{~s}^{-1}$, measured using a QSL-100 quantum sensor (Biospherical Instruments Inc., San Diego, USA). After 20 days of growth, the cultures were centrifuged in an Eppendorf 5804R centrifuge at 15,000 g for 10 min at $4{ }^{\circ} \mathrm{C}$ (Eppendorf AG, Hamburg, Germany). The supernatant was then discarded, and the pellets were stored at $-20^{\circ} \mathrm{C}$ and then lyophilized in a lyophilizer model Liotop L101 to obtain dry cells (Liobras, São Carlos, Brazil).

\section{Guanitoxin identification by LC-ESI-Q-TOF-MS}

Lyophilized samples (10 $\mathrm{mg}$ triplicates) were extracted with methanol/water (70:30 v/v) and 0.3\% acetic acid using the Omni Sonic Ruptor 400 ultrasonic homogenizer with a pulse of $30 \%$ for $3 \mathrm{~min}$ for three cycles (OMNI International Company, Georgia, USA). Samples were centrifuged at $15,000 \mathrm{~g}$, for $10 \mathrm{~min}$ at $4{ }^{\circ} \mathrm{C}$ (Eppendorf AG, Hamburg, Germany). The supernatants were filtered through $0.22 \mu \mathrm{m}$ polyvinylidene difluoride (PVDF) membranes (Nova Analítica, São Paulo, Brazil).

The identification of GNT was performed by high performance liquid chromatography (HPLC) using an LC-20D chromatograph (Shimadzu, Kyoto, Japan) coupled to a micrOTOF-Q II electrospray ionization quadrupole time-of-flight mass spectrometer (ESI-Q-TOF-MS) (Bruker Daltonics Corporation, Bremen, Germany).

The mass spectrometer was operated in positive ionization source mode, with $4000 \mathrm{~V}$ capillary potential, drying nitrogen gas flow $\left(6 \mathrm{~mL} \mathrm{~min}^{-1}\right.$ at $\left.200{ }^{\circ} \mathrm{C}\right)$, and a nebulizer nitrogen pressure of 35 psi. Data were collected from $m / z, 60$ to 800 at an acquisition rate of $2 \mathrm{~Hz}$, and the 
variable number of ions was selected by automatic full scan and auto MS/MS scan fragmentation with a cycle time of $2.5 \mathrm{~s}$.

Hydrophilic interaction liquid chromatography (HILIC) separation was performed on a zwitterionic (ZIC) column $150 \times 2.1 \mathrm{~mm}, 5 \mu \mathrm{m}$ particles, and $200 \AA$ pore size. The chromatographic method was based on the method described by Dörr et al., ${ }^{13}$ however we changed the concentration and flow of the mobile phases in order to reduce the time of our analyzes (Table S1 in the Supplementary Information (SI) section).

The mobile phase was delivered at a flow rate of

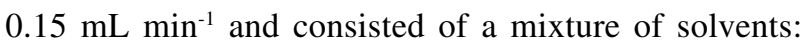
A $\left(\mathrm{H}_{2} \mathrm{O}\right.$ with $0.04 \%$ formic acid; $10 \mathrm{mM}$ ammonium formate $\mathrm{v} / \mathrm{v}$ ), and $\mathrm{B}$ (acetonitrile: $\mathrm{H}_{2} \mathrm{O}(80: 20)$ with $0.01 \%$ formic acid and $5 \mathrm{mM}$ ammonium formate, v/v). GNT analyses were performed on a linear gradient with 90 to $40 \%$ (B) from $0-10 \mathrm{~min}$, then maintained at $40 \%$ (B) 10-12 min, increasing to $90 \%$ (B) from $12-12.5 \mathrm{~min}$, and maintained $90 \%$ (B) $12.5-20 \mathrm{~min}$.

Data were acquired using Bruker Compass Data Analysis 4.0 software (Bruker Daltonics Corporation, Bremen, Germany), where it was possible to calculate the experimental mass and the molecular formula of the toxin $(\mathrm{GNT})$ and its product ions $[\mathrm{M}+\mathrm{H}]^{+}$with errors $<5 \mathrm{ppm}$ and $<10$ millisigma value (mSigma).

\section{Analysis of guanitoxin by LC-QqQ-MS/MS}

The data was analyzed qualitatively in an Agilent 1260 Infinity HPLC system coupled to a mass spectrometer 6460 triple quadrupole (QqQ-MS/MS) (Agilent Technologies, Santa Clara, USA), with ESI in positive mode. Nitrogen was used as the gas nebulizer (45 psi), with drying gas $\left(5 \mathrm{~mL} \mathrm{~min}^{-1}\right.$ at $300{ }^{\circ} \mathrm{C}$ ), and sheath gas temperature of $11 \mathrm{~min}^{-1}$ at $280{ }^{\circ} \mathrm{C}$. The capillary high voltage was set to $4000 \mathrm{~V}$. Chromatographic separation was performed using a ZIC-HILIC SeQuant column- $150 \times 2.1 \mathrm{~mm}, 5 \mu \mathrm{m}$, $200 \AA$ (Merck, Darmstadt, Germany) at a flow rate of $0.15 \mathrm{~mL} \mathrm{~min}^{-1}$. The mobile phases and the gradient used to elute GNT followed the same conditions described in the method of LC-MS.

The injection volume used for the analyses was $5 \mu \mathrm{L}$. Identification of GNT and qualitative analyses were performed considering its retention time and peak area, determined by MS/MS tandem analyses in multiple reaction monitoring (MRM) positive mode $[\mathrm{M}+\mathrm{H}]^{+}$, monitoring the ionic products of $\mathrm{m} / \mathrm{z} 253>58$ and $\mathrm{m} / \mathrm{z} 253>159 .{ }^{13}$ In this study, we proposed the transition $\mathrm{m} / \mathrm{z} 159>58$ to monitor the GNT degradation product ${ }^{1-26}$ formed from the neutral loss of the methyl phosphate group. ${ }^{13}$ Data were acquired using MassHunter Qualitative B.07.00 software (Agilent Technologies, Santa Clara, USA) and molecular structures were designed using ChemDraw Ultra software (PerkinElmer, Waltham, USA). ${ }^{19}$

Stability assays: preparation of solutions with different $\mathrm{pH}$ values

Conditions of extraction and $\mathrm{pH}$ considered the protocol established by Mahmood and Carmichael. ${ }^{3}$ Acid solutions with $\mathrm{pH}$ values of 1.5 and 5.0 were prepared using $0.1 \mathrm{M}$ hydrochloric acid and adjustments with $0.1 \mathrm{M}$ sodium hydroxide. ${ }^{20}$ The solution with a $\mathrm{pH}$ value of 3.0 was prepared with $0.3 \%$ acetic acid.

We used only ultra-pure water $(\mathrm{pH} 6.8-7.0)$ as neutral

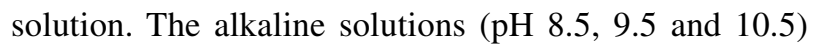
were prepared using ultra-pure water, monobasic sodium phosphate, monobasic potassium phosphate $0.1 \mathrm{M}$, and $\mathrm{pH}$ was adjusted with ammonium hydroxide $0.1 \mathrm{M}$ and phosphoric acid $0.1 \mathrm{M} .{ }^{21}$ The $\mathrm{pH}$ values were measured with a Metrohm digital pH meter model 827 pH Lab/6.0224.100 combined with a glass electrode (Metrohm, Herisau, Switzerland).

Stability assays: dry cell samples stored at different temperatures

The methodology used was carried out to evaluate the stability and viability of the storage of lyophilized cell samples of the ITEP-24 strain at different temperatures. The experiments were carried out with freshly grown cultures of ITEP-24. Samples containing $10 \mathrm{mg}$ of dry cells were separated and conditioned under different temperatures: $-80,-20,4$, and $23{ }^{\circ} \mathrm{C}$ for 180 days. In total, 18 samples from each condition were used. Samples (in triplicate) were extracted with $1 \mathrm{~mL}$ ultra-pure $\mathrm{H}_{2} \mathrm{O}$ acidified with $0.3 \%$ acetic acid at 30-day intervals totaling 180 days.

Extraction was carried out by freezing and thawing cycles $\left(-20\right.$ and $\pm 25{ }^{\circ} \mathrm{C}$ ) for six consecutive times at intervals of up to one hour. The samples were then centrifuged at $15,000 \mathrm{~g}, 4^{\circ} \mathrm{C}$ for $10 \mathrm{~min}$ (Eppendorf AG, Hamburg, Germany). The supernatants were filtered through $0.45 \mu \mathrm{m}$ PVDF membranes (Nova Analítica, São Paulo, Brazil) and samples were qualitatively analyzed by LC-MS/MS; the samples remained at an ambient temperature of ca. $23{ }^{\circ} \mathrm{C}$ during the analyses.

\section{Stability assays: fresh vs. lyophilized cells}

This experiment was to evaluate GNT stability in lyophilized samples stored for a long period vs. fresh 
samples. GNT containing samples were stored $\left(-20^{\circ} \mathrm{C}\right.$ for 1 year) and fresh cells were recently dried by lyophilization. For experiments with freshly lyophilized cells, we used $20 \mathrm{~mL}$ of cultures (in triplicate), and processes involving centrifugation and lyophilization were immediately carried out. Subsequently the pellets were weighed, resulting in a dry weight of approximately $7.0 \mathrm{mg}$ (in triplicate). The same weight (ca. $7 \mathrm{mg}$ in triplicate) was used for the lyophilized cells stored for 1 year. Samples were extracted with $1 \mathrm{~mL}$ of water and acetic acid $0.3 \%$. The samples were submitted to a freezing and thawing cycle six times and were then centrifuged, filtered, and analyzed by LCMS/MS.

Stability assays: extraction of dry cells (from pH 1.5 to 9.5)

Approximately $10 \mathrm{mg}$ of dry cells (in triplicate) were used and samples were prepared with $1 \mathrm{~mL}$ of the solutions ( $\mathrm{pH}$ values of: 1.5, 3.0, 5.0, 7.0, and 9.5). Extractions were performed by freezing and thawing cycles six times followed by centrifugation and filtration as described above, and injected into the LC-MS/MS. Samples were injected into the LC-MS at $0,24,48,72$, and $96 \mathrm{~h}$ and remained at room temperature (ca. $23{ }^{\circ} \mathrm{C}$ ).

\section{Stability assays: extraction from fresh cells}

A $5 \mathrm{~mL}$ volume of the ITEP-24 strain culture (in triplicate) was used, the samples were centrifuged $(15,000 \mathrm{~g}$, $4{ }^{\circ} \mathrm{C}, 10 \mathrm{~min}$ ), supernatant was discarded, and pellets were used in the experiments. Extractions were performed with solutions under $\mathrm{pH}$ of 1.5, 3.0, 5.0, 7.0, 8.5, and 10.5. The samples were then submitted to an Elma E60 Elmasonic ultrasonic homogenizer in a water bath at $37^{\circ} \mathrm{C}$ for $1 \mathrm{~h}$ (Nova Analitica, São Paulo, Brazil). After extraction, samples were centrifuged, filtered, and analyzed in LC-MS/MS (transitions $m / z 253>58$ and $m / z 253>159[\mathrm{M}+\mathrm{H}]^{+}$), with injections at $0,24,48,72$, and $96 \mathrm{~h}$.

\section{Degradation product of guanitoxin}

We used ca. $10 \mathrm{mg}$ (in triplicate) of dry cells, and extractions were performed with $1 \mathrm{~mL}$ of ultrapure $\mathrm{H}_{2} \mathrm{O}$ with $0.3 \%$ acetic acid, $\mathrm{pH} 3.0$. Samples were submitted to the ultrasonic homogenizer with a pulse of $30 \%$ for $3 \mathrm{~min}$ for three cycles (OMNI International Company, Georgia, USA), then centrifuged, and filtered. After GNT extraction, $1 \mathrm{M}$ sodium hydroxide was added to adjust samples to $\mathrm{pH}=10.5$. The samples were then analyzed by LC-MS/MS; with injections at 0, 24, 48, 72, 96, 120 and $144 \mathrm{~h}$. Samples were kept at room temperature $\left(\right.$ ca. $\left.23^{\circ} \mathrm{C}\right)$. We evaluated the relationship between the formation of the toxin degradation product and the decrease in the GNT biological activity, through ions $159>58,253>58$ and $253>159$, respectively.

\section{Statistical analyses}

The data were normalized (\%) and presented from the mean \pm standard deviation. The comparisons between groups were performed using two-way analysis of variance (ANOVA) tests, followed by the Tukey's test for multiple comparisons. The difference between treatments was considered by the confidence interval $(\alpha \leq 0.05)$ using GraphPad Prism software (GraphPAD Software, San Diego, USA). ${ }^{22}$

\section{Results and Discussion}

\section{LC-MS and LC-MS/MS methods}

Although there is no analytical standard for quantifying GNT in environmental samples, the chromatographic method and the analysis by high-resolution mass spectrometry have become especially important for the correct identification of the toxin, as well as its monitoring in bodies of water. The GNT chromophore group does not appear to be strong enough to be detected in HPLC systems with a diode array detector, in addition, the toxin has low molecular weight and high polarity ( $\log \mathrm{P}=-1.7)$ and therefore, ${ }^{4}$ low retention in reverse phase $\mathrm{C} 18$ columns. ${ }^{13}$

For these reasons, the toxin identification and detection in this study was performed by HPLC combination of MS with an ionization source ESI in positive mode; chromatographic separation was performed by HILIC with a ZIC column showing adequate retention time (7.5 to $8.0 \mathrm{~min}$ ) and peak format for GNT. We obtained excellent results from the chromatography method described here, making it possible to separate the toxin from various interferents present in the crude extract. The fragmentation profile of GNT was similar to the study by Dörr et al. ${ }^{13}$ and Rodríguez et al.; ${ }^{23}$ however we carried out our experiments on two different mass spectrometer analyzers (triple quadrupole-QqQ and quadrupole time-of-flight (TOF) detectors). The authors mentioned above $\mathrm{e}^{13,23}$ used an ion trap detector, therefore we had to readapt these chromatographic conditions and equipment parameters.

GNT identification was generated based on the protonated exact mass $[\mathrm{M}+\mathrm{H}]^{+}$, isotopic pattern, and $\mathrm{MS}^{2}$ fragmentation spectrum (Figure S1a, SI section), where experimental $\mathrm{m} / \mathrm{z}$ was equal to 253.1057 (Figure S1b), theoretical/calculated $\mathrm{m} / \mathrm{z}$ was 253.1060, 
molecular formula was $\mathrm{C}_{7} \mathrm{H}_{18} \mathrm{~N}_{4} \mathrm{O}_{4} \mathrm{P}$, error in $\mathrm{ppm}=1.0$, and mSigma $=1.2 . \mathrm{MS}^{2}$ presents GNT characteristic fragmentation ions in positive mode: $m / z 96.0556\left(\mathrm{C}_{4} \mathrm{H}_{6} \mathrm{~N}_{3}\right)$, and $m / z 159.1240\left(\mathrm{C}_{6} \mathrm{H}_{15} \mathrm{~N}_{4} \mathrm{O}\right)$. Other ions can also be used for GNT confirmation: $m / z, 98.0713\left(\mathrm{C}_{4} \mathrm{H}_{8} \mathrm{~N}_{3}\right)$ and $m / z \quad 123.0553\left(\mathrm{C}_{6} \mathrm{H}_{7} \mathrm{~N}_{2} \mathrm{O}\right)$ (Figure $\left.\mathrm{S} 1 \mathrm{c}\right) .{ }^{15}$ However, the fragmentation profile of the molecule may vary, depending on the equipment used, and the chromatographic method and low stability ions are more susceptible to these variables.

Toxin detection was performed in MRM modes, using precursor ion $m / z, 253[\mathrm{M}+\mathrm{H}]^{+}$and ionic transitions $m / z, 253>58$ and $m / z 253>159$ (Figure S2, SI section). The transition $m / z 253>58$ can be used to quantify the toxin, due to the intensity and stability ion of $m / z, 58 . .^{13,23}$ We also used the transition $m / z, 159>58$ proposed in this study, to monitor the GNT degradation product, after the neutral loss of the methyl phosphate group (Figure S2). After all these considerations, our hypothesis was based on the monitoring of $\mathrm{m} / \mathrm{z} 159[\mathrm{M}+\mathrm{H}]^{+}$that best represents the degradation product. As a consequence, we can also see a decrease in the main protonated ion for the toxin itself $\mathrm{m} / \mathrm{z} 253[\mathrm{M}+\mathrm{H}]^{+}$. Although the triple-quadrupole is a lowresolution mass analyzer, the ionic transitions mentioned in this study in MRM mode made possible the GNT detection, even when the toxin was in alkaline solutions prepared at a temperature of 23 and $37^{\circ} \mathrm{C}$.

For this reason, triple-quadrupole equipment becomes an excellent ally in the detection of the GNT molecule, allowing the rapid screening of GNT in complex samples, such as environmental samples. However, the definition of the chromatographic method and adequate sample preparation are especially important to identify and detect the toxin, due to the instability of the molecule to some environmental variables.

\section{Guanitoxin stability}

The results presented in Figures 1-5 (\%) were acquired from samples of the strain ITEP-24 submitted to different extraction conditions, temperature, $\mathrm{pH}$, and storage time analyzed by LC-MS/MS. The raw data from the LC-MS/MS analyzes are available in the SI section Tables S2 to S6. Figure 1 shows data from lyophilized samples of the ITEP-24 strain stored at four different temperatures for a period of 180 days.

These samples were extracted every 30 days to assess the stability of the GNT. During the experiment we observed that the toxin gradually degraded at all temperatures, with a $p$-value $<0.05$ from the initial to the end of the experiment. The degradation of GNT was more severe in samples conditioned at $23{ }^{\circ} \mathrm{C}$ after 30 days of exposure compared to other temperatures ( $p$-value $<0.0001)$.

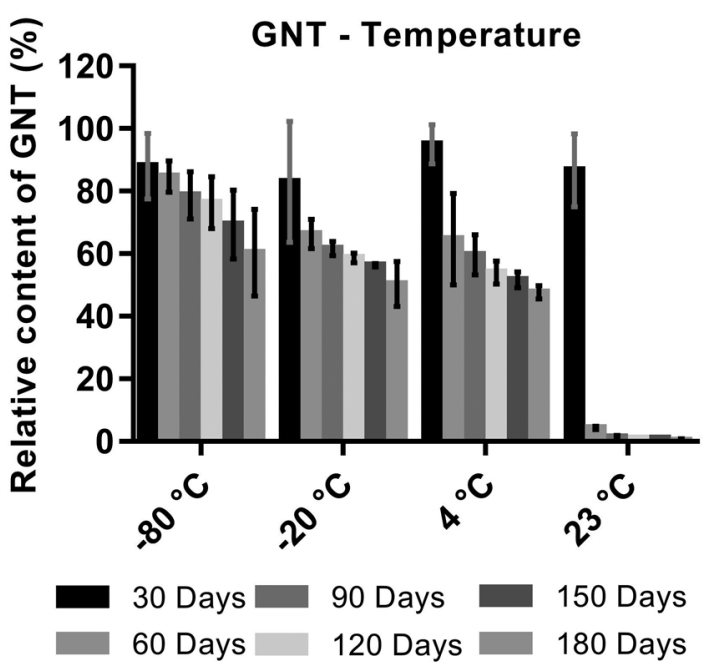

Figure 1. GNT stability in lyophilized samples of the conditioned ITEP24 strain $-80,-20$ and $4{ }^{\circ} \mathrm{C}$ and $23{ }^{\circ} \mathrm{C}$ for 180 days. The data were acquired by LC-MS/MS in MRM mode using transitions $(\mathrm{m} / \mathrm{z} 253>58$ and $\left.m / z, 253>159[\mathrm{M}+\mathrm{H}]^{+}\right)$. The graph shows the degradation of the toxin in samples stored at $23{ }^{\circ} \mathrm{C}$ after 30 days ( $p$-value $<0.0001$ ); there was also gradual degradation of the toxin in samples conditioned at -80 , -20 and $4{ }^{\circ} \mathrm{C}(p$-value $<0.05)$.

Interestingly, the peak area values at the initial temperature ( 30 days) at $-80^{\circ} \mathrm{C}$ were lower $(p$-value $<0.05)$ compared to the same period at $-20,4$ and $23^{\circ} \mathrm{C}$. Among the temperatures evaluated, the toxin showed greater stability at $-20{ }^{\circ} \mathrm{C}$. Some studies report the loss of biological activity of GNT after six and four months of storage at $-20{ }^{\circ} \mathrm{C}$, and two weeks without preservation. ${ }^{8,24}$ Nevertheless, our study only evaluated the feasibility of storing dry biomass containing the toxin at different temperatures, and this must be considered.

In addition to evaluating the influence of different temperatures on the GNT molecule, we also tested the stability of the toxin from extractions in fresh cells and lyophilized cells that were stored in a freezer at $-20{ }^{\circ} \mathrm{C}$ for 1 year (Figure 2). These experiments aimed to evaluate the feasibility of storing lyophilized samples for long periods. That is why we used lyophilized cells from an old sample and a "fresh" sample, both obtained from cultures of the ITEP-24 strain grown under the same conditions. The results showed that the relative concentration of GNT obtained from freshly lyophilized (fresh) cells was higher compared to the extractions performed on samples kept for a period of 1 year ( $p$-value $<0.0001)$.

The information available in the literature reports that the toxin is unstable in alkaline solutions (half-life of approximately one hour at $\mathrm{pH}>8.5) .{ }^{19}$ Our results show that the toxin decomposes quickly in alkaline solutions, 


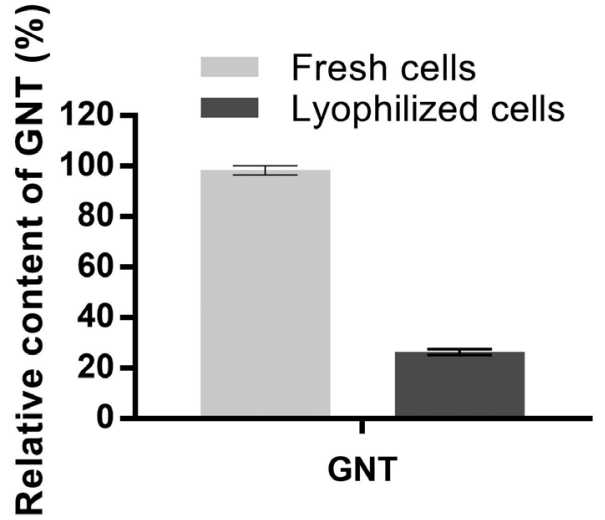

Figure 2. GNT extraction performed with lyophilized cells stored for 1 year $\left(-20^{\circ} \mathrm{C}\right)$ and fresh cells that were lyophilized and immediately analyzed. The data were obtained through analysis by LC-MS/MS in MRM mode $\left(\mathrm{m} / z 253>58\right.$ and $\left.\mathrm{m} / z 253>159[\mathrm{M}+\mathrm{H}]^{+}\right)$. The results show that extractions performed directly from fresh cells are statistically significant ( $p$-value $<0.0001)$.

but the half-life differs from the data in the literature; in our experiments, the toxin hydrolyzed in an interval $\geq 96 \mathrm{~h}$. Here, we evaluate the degradation at different time intervals from those reported in the literature; however, if we compare the initial time with the later time, the peak area declines in all $\mathrm{pH}$ solutions and is statistically more significant $(p$-value $<0.05)$ in neutral to alkaline $\mathrm{pH}$ solutions (Figure 3).

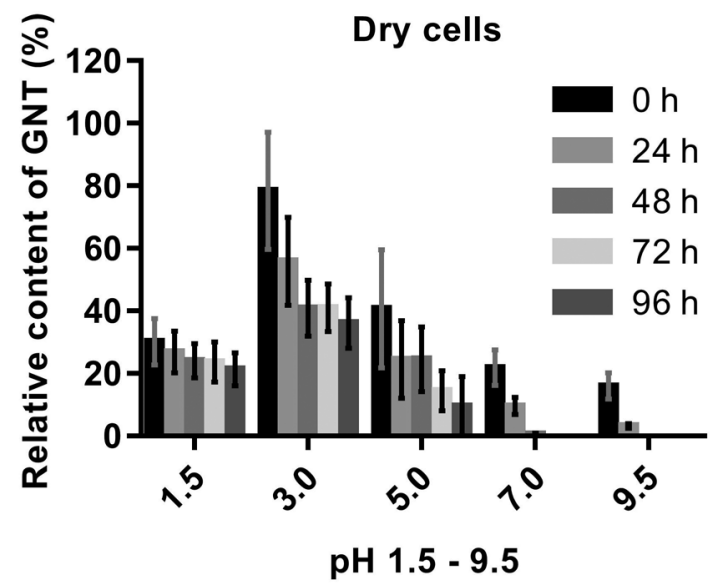

Figure 3. Stability of GNT extracted from lyophilized cells of the ITEP24 strain at different $\mathrm{pH}$ with intervals of $24 \mathrm{~h}$ for $96 \mathrm{~h}$. The data were obtained through analysis by LC-MS/MS in MRM mode $(\mathrm{m} / z, 253>58$ and $\left.m / z 253>159[\mathrm{M}+\mathrm{H}]^{+}\right)$. The graph shows that GNT is more stable at acidic $\mathrm{pH}$, with $\mathrm{pH} 3.0$ being better for its stability ( $p$-value $<0.05$ ). There was no statistical difference in the concentration of GNT extracted in solutions with $\mathrm{pH} 1.5$ and 5.0 and between $\mathrm{pH} 7.0$ and 9.5.

Figure 3 shows that GNT is more stable at acid $\mathrm{pH}$, and $\mathrm{pH} 3.0$ proved to be the best for toxin stability ( $p$-value $<0.05$ ). The multiple comparison tests (Tukey) were used to compare the peak GNT area and the respective treatments, showing that there was no statistical difference between $\mathrm{pH} 1.5$ and 5.0, and $\mathrm{pH} 7.0$ and 9.5 treatments
( $p$-value $>0.05)$. A comparison was subsequently made between temperature and peak area of the GNT, showing that the 0 -h time is statistically different to the others ( $p$-value $<0.05)$.

Figure 4 shows that from 0 to $96 \mathrm{~h}$, the solutions at $\mathrm{pH} 1.5$ and $\mathrm{pH} 3.0$ were statistically different, $p$-value $<0.05$, while $\mathrm{pH}$ 5.0, 7.0, 8.5, and 10.5 showed no statistical difference between them. The results show that the stability of GNT extracted in dry and fresh cells was similar. However, the concentration of the toxin is higher in samples extracted directly from fresh cells. It is important to note that cell lysis was applied differently; in the test with lyophilized cells, we applied freeze and thawing $\left(-20\right.$ and $\left.23{ }^{\circ} \mathrm{C}\right)$ while in the experiment with fresh cells the samples were submitted to ultrasound with a $37^{\circ} \mathrm{C}$ water bath. In both experiments, samples were lysed for $1 \mathrm{~h}$. However, the concentration of the toxin is higher in samples extracted directly from fresh cells, even though they are lysed at a higher temperature $\left(37^{\circ} \mathrm{C}\right)$.

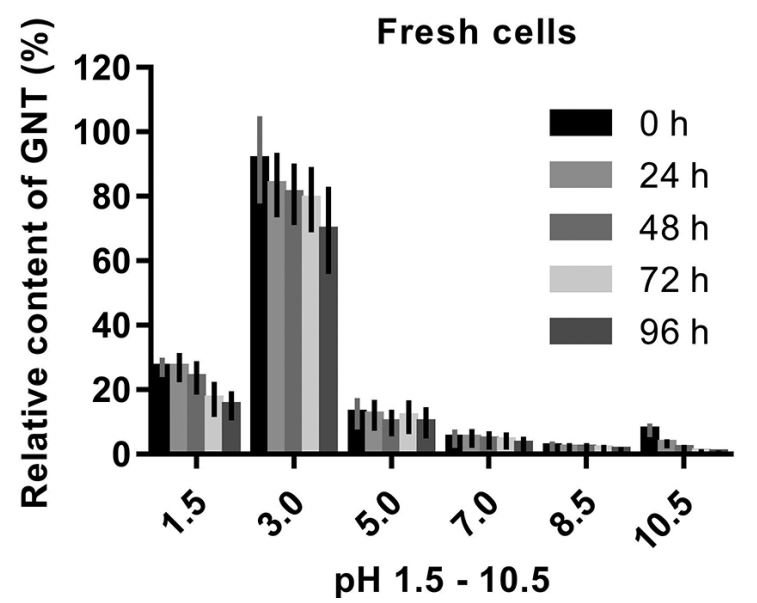

Figure 4. Evaluation of the stability of GNT extracted from fresh cells of the ITEP-24 strain in solutions with $\mathrm{pH}$ values of 1.5 to 10.5 at $37^{\circ} \mathrm{C}$. Data were acquired by LC-MS/MS in MRM mode $(\mathrm{m} / z, 253>58$ and $\left.m / z, 253>159[\mathrm{M}+\mathrm{H}]^{+}\right)$. The $\mathrm{pH} 3.0$ differed statistically $(p$-value $<0.05)$ from other $\mathrm{pH}$ solutions at all sampling times. In neutral solutions and alkaline $\mathrm{pH}$, the extracted toxin was degraded as a function of exposure time. Statistical analysis showed that $0-96 \mathrm{~h}$ at $\mathrm{pH} 1.5$ and 3.0 were statistically different from the others, while $\mathrm{pH}$ 5.0, 7.0, 8.5 and 10.5 have no statistical difference per se.

Our results showed that the GNT molecule did not completely degrade in alkaline $\mathrm{pH}$ and temperature above $23{ }^{\circ} \mathrm{C}$ in less than $96 \mathrm{~h}$. However, the molecule did not degrade totally under the conditions used in the study. According to Matsunaga et al. ${ }^{1}$ and Barros et al. ${ }^{24}$ GNT is a high-temperature sensitive molecule $>40{ }^{\circ} \mathrm{C}$. In our study, we analyzed freeze-dried and fresh samples at different temperatures in order to study the best condition to store samples in the laboratory and evaluate the half-life of the extracellular toxin at temperatures observed in cyanobacterial blooms. ${ }^{25}$ 
Figure 5 shows the degradation profile of the GNT for the ITEP-24 strain referring to samples that were extracted in acidic $\mathrm{pH} 3.0$ and then alkalized $\mathrm{pH} 10.5$. The peak area of the GNT gradually decreased, while the peak of the GNT degradation product increased significantly after 96 to $144 \mathrm{~h}$ (Figures 5 and S3). In this study, we monitored the degradation product of GNT by LC-MS/MS from the transition $\mathrm{m} / z 159>58[\mathrm{M}+\mathrm{H}]^{+}$(Scheme 1). The proposed mechanism of guanitoxin fragmentation in gas phase using ESI positive mode adapted from Dörr et al. ${ }^{13}$ shows the formation of ion $\mathrm{m} / z 159[\mathrm{M}+\mathrm{H}]^{+}$after the neutral loss of methyl phosphate residue. ${ }^{1,13,26}$ Throughout the analysis, we also observed that the GNT degradation product was more common in dry cell samples. In fresh cell samples, this ion $\left(\mathrm{m} / z 159[\mathrm{M}+\mathrm{H}]^{+}\right)$was rarely observed; it was basically present in the samples after extractions in solution with pH 7.0 to 10.5 and the samples of dry cells kept at room temperature.

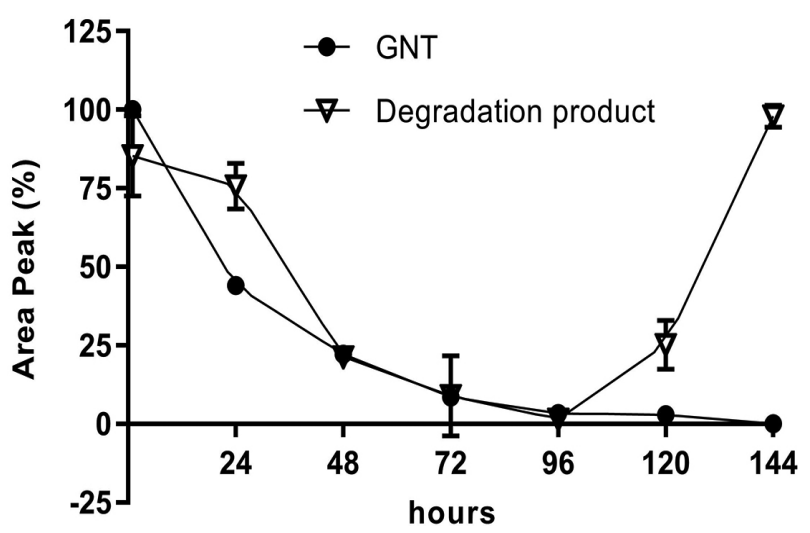

Figure 5. Degradation profile of GNT present in lyophilized cells of the ITEP-24 strain analyzed by LC-MS/MS in MRM mode. The graph shows normalized data in percent of the peak area of GNT for transitions $\mathrm{m} / z 253>159[\mathrm{M}+\mathrm{H}]^{+}$, and $\mathrm{m} / z 253>58[\mathrm{M}+\mathrm{H}]^{+}$decreases after treatment with sodium hydroxide $\mathrm{pH} 10.5$, while the degradation of the product $m / z, 159>58[\mathrm{M}+\mathrm{H}]^{+}$increases significantly $(p$-value $<0.05)$ after $96 \mathrm{~h}$.

In organisms, GNT inhibits AChE by a phosphorylation of an $\mathrm{OH}$ serine residue present in $\mathrm{AChE}$, and its dephosphorylated analogue is formed, according to Hyde and Carmichael. ${ }^{26}$ The action mechanism consists of the irreversible inhibition of the enzyme AChe, a mechanism similar to that of organophosphate insecticides. AChe inhibition prevents acetylcholine hydrolysis, inducing acute effects characteristics of a cholinergic syndrome due to excess acetylcholine at the neuromuscular junction.

Although GNT has a short half-life, its presence in the environment has been responsible for the mortality of birds and mammals after consumption of water containing toxin-producing cyanobacterial cells. GNT has been identified in different regions of America,,${ }^{11,27}$ Europe, ${ }^{7}$ and

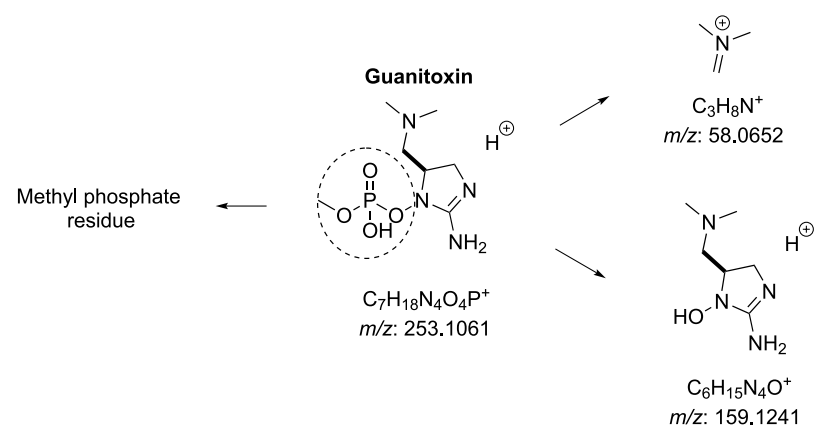

Scheme 1. Gas phase guanitoxin fragmentation using positive ESI mode used to monitor the formation of the ion $\mathrm{m} / z 159[\mathrm{M}+\mathrm{H}]^{+}$after neutral loss of the methyl phosphate residue.

recently in Asia ${ }^{10,28}$ in eutrophic environments of fresh and terrestrial water. The predominance of these organisms in the water body directly interferes with some important physicochemical variables essential for the balance of aquatic ecosystems. ${ }^{29}$

In the natural environment, cyanobacterial blooms are directly related to the climatic conditions of a given region and the availability of nutrients in the water (nitrogen and phosphorus). ${ }^{30-32}$ Most cyanobacterial bloom reports occur in summer and early autumn with temperatures $>15{ }^{\circ} \mathrm{C} .{ }^{33}$ The $\mathrm{pH}$ also influences the development of cyanobacteria, the optimal growth range of these microorganisms occurs at a $\mathrm{pH}$ of 7.5 to 10 , being inhibited at a pH below 5 . In continental waters the $\mathrm{pH}$ usually presents values in the range of 6 to 8 and can be also predominantly alkaline during the cellular respiration process carried out by algae and cyanobacteria, where by-products can form, leaving the water alkalized. ${ }^{34}$ The sum of these factors justifies the success and dominance of specific cyanobacterial species, and consequently, the relationship of toxins identified in bloom events. ${ }^{35}$ In addition to the presence of cyanotoxins, cyanobacterial blooming events can cause oxygen depletion, and consequently the death of more fragile organisms.

Although GNT has a short half-life, because of its instability to environmental variables ( $\mathrm{pH}$ and temperature) compared to other cyanotoxins such as microcystins, the occurrence of GNT-producing species has already been reported in aquatic environments in different locations in the world, causing deaths of animals in a short period. Thus, the results of our study show that extracellular GNT can remain at neutral and alkaline $\mathrm{pH}$ for more than $24 \mathrm{~h}$, forcing the need for active monitoring of this toxin in aquatic environments. Although there is no specific legislation for monitoring GNT, nor an analytical standard for its quantification in bodies of water, the methodologies presented in this study are sufficient for the correct diagnosis of the molecule in biological samples, in order to avoid the loss of quality water for human consumption, 
as well as preventing the death of aquatic and terrestrial organisms.

\section{Conclusions}

We have shown that GNT is a very sensitive molecule to some environmental variables, and can be degraded in a period of up $\geq 96 \mathrm{~h}$, especially in an alkaline environment. Our study also found that GNT present in lyophilized cells degrades significantly at a temperature of $23{ }^{\circ} \mathrm{C}$ for 30 days. In addition, we identified that the toxin present in lyophilized cells kept frozen (ca. $-20^{\circ} \mathrm{C}$ ) for long periods may degrade in comparison with samples acquired directly from fresh cells. Based on our stability studies, we strongly recommend sample preparation and analyses as soon as a material is harvested from the environment, from cultured cells, or biological tissues. The LC-MS and LC-MS/MS methods employed in this study can be easily used to determine GNT in samples with different $\mathrm{pH}$ values; however, at alkaline $\mathrm{pH}$ the toxin was detected in very low concentrations, as well as its total degradation, due to its sensitivity to alkaline $\mathrm{pH}$.

\section{Supplementary Information}

Mass spectra of GNT (MS and $\mathrm{MS}^{2}$ ) obtained from LC-ESI-Q-TOF-MS analyses and table with chromatographic method, as well as the total ion chromatograms in various reaction monitoring modes (MRM), extracted ion chromatograms, and tables with relative peak area values monitored in LC-QqQ-MS/MS are available free of charge at http://jbcs.sbq.org.br as a PDF file.

\section{Acknowledgments}

This work was supported by the São Paulo State Research Foundation (FAPESP) through a grant (2014/50420-9), University of São Paulo Foundation (FUSP) (project No. 1979), the Coordination for the Improvement of Higher Education Personnel (CAPES) (project No. 23038.001401/2018-92) and National Council for Scientific and Technological Development (CNPq) (311048/2016-1 and 439065/2018-6).

\section{References}

1. Matsunaga, S.; Moore, R. E.; Niemczura, W. P.; Carmichael, W. W.; J. Am. Chem. Soc. 1989, 111, 8021.

2. Fiore, M. F.; de Lima, S. T.; Carmichael, W. W.; McKinnie, S. M. K.; Chekan, J. R.; Moore, B. S.; Harmful Algae 2020, 92, 101737.
3. Mahmood, N. A.; Carmichael, W. W.; Toxicon 1986, 24, 425.

4. Mahmood, N. A.; Carmichael, W. W.; Toxicon 1987, 25, 1221.

5. Cook, W. O.; Iwamoto, G. A.; Schaeffer, D. J.; Beasley, V. R.; J. Environ. Pathol., Toxicol. Oncol. 1989, 9, 393.

6. Mahmood, N. A.; Carmichael, W. W.; Pfahler, D.; Am. J. Vet. Res. 1988, 49, 500.

7. Henriksen, P.; Carmichael, W. W.; An, J.; Moestrup, Ø.; Toxicon 1997, 35, 901.

8. Onodera, H.; Oshima, Y.; Henriksen, P.; Yasumoto, T.; Toxicon 1997, 35, 1645.

9. Briand, J.-F.; Jacquet, S.; Bernard, C.; Humbert, J.-F.; Vet. Res. 2003, 34, 361.

10. Chatziefthimiou, A. D.; Richer, R.; Rowles, H.; Powell, J. T.; Metcalf, J. S.; Vet. Rec. 2014, 174, 484.

11. Molica, R. J. R.; Oliveira, E. J. A.; Carvalho, P. V. V. C.; Costa, A. N. S. F.; Cunha, M. C. C.; Melo, G. L.; Azevedo, S. M. F. O.; Harmful Algae 2005, 4, 743.

12. Freitas, E. C.; Printes, L. B.; Rocha, O.; Harmful Algae 2016, $55,150$.

13. Dörr, F. A.; Rodríguez, V.; Molica, R.; Henriksen, P.; Krock, B.; Pinto, E.; Toxicon 2010, 55, 92.

14. Santos, D. S.; Rosa, M. E.; Zanatta, A. P.; Oliveira, R. S.; de Almeida, C. G. M.; Leal, A. P.; Sanz, M.; Fernandes, K. A.; de Souza, V. Q.; de Assis, D. R.; Ecotoxicol. Environ. Saf. 2019, $171,138$.

15. Svirčev, Z.; Lalić, D.; Savić, G. B.; Tokodi, N.; Backović, D. D.; Chen, L.; Meriluoto, J.; Codd, G. A.; Arch. Toxicol. 2019, 93, 2429.

16. Moura, S.; Pinto, E.; Synlett 2010, 967.

17. Gorham, P. R.; McLachlan, J.; Hammer, U. T.; Kim, W.; Verh. - Int. Ver. Theor. Angew. Limnol. 1964, 15, 1964.

18. Werner, V. R.; Laughinghouse IV, H. D.; Fiore, M. F.; Sant'Anna, C. L.; Hoff, C.; Santos, K. R. S.; Neuhaus, E. B.; Molica, R. J. R.; Honda, R. Y.; Echenique, R. O.; Phycologia 2012, 51, 228.

19. Evans, D. A.; Rubenstein, S.; ChemDraw Ultra, version 12.0; CambridgeSoft Corporation/PerkinElmer, USA, 2010.

20. Kaminski, A.; Bober, B.; Lechowski, Z.; Bialczyk, J.; Harmful Algae 2013, 28, 83.

21. Al Momani, F.; Sep. Purif. Technol. 2007, 57, 85.

22. GraphPad Prism, version 7.0 for Windows.; GraphPad Software, USA, 2019.

23. Rodríguez, V.; Mori, B.; Dörr, F. A.; dal Belo, C. A.; Colepicolo, P.; Pinto, E.; Rev. Bras. Farmacogn. 2012, 22, 775.

24. Barros, L. P. C.; Monserrat, J. M.; Yunes, J. S.; Environ. Toxicol. Chem. 2004, 23, 883.

25. Rapala, J.; Sivonen, K.; Microb. Ecol. 1998, 36, 181.

26. Hyde, E. G.; Carmichael, W. W.; J. Biochem. Toxicol. 1991, 6, 195.

27. Carmichael, W. W.; Gorham, P. R.; Verh. - Int. Ver. Theor. Angew. Limnol. 1978, 21, 285. 
28. Metcalf, J. S.; Richer, R.; Cox, P. A.; Codd, G. A.; Sci. Total Environ. 2012, 421-422, 118.

29. Wagner, C.; Adrian, R.; Limnol. Oceanogr. 2009, 54, 2460.

30. Cong, L.; Huang, B.; Chen, Q.; Lu, B.; Zhang, J.; Ren, Y.; Anal. Chim. Acta 2006, 569, 157.

31. Yang, J.; Lv, H.; Liu, L.; Yu, X.; Chen, H.; Sci. Total Environ. 2016, $557,445$.

32. Walker Jr., W. W.; J. - Am. Water Works Assoc. 1983, 75, 38.
33. Chorus, I. In Cyanotoxins: Occurrence, Causes, Consequences; Chorus, I., ed.; Springer: Berlin, Germany, 2001.

34. Ji, X.; Verspagen, J. M. H.; Stomp, M.; Huisman, J.; J. Exp. Bot. 2017, 68, 3815.

35. Karjalainen, M.; Engstrom-Ost, J.; Korpinen, S.; Peltonen, H.; Paakkonen, J. P.; Ronkkonen, S.; Suikkanen, S.; Viitasalo, M.; Ambio 2007, 36, 195. 